\section{Commentary: There's more than one way to skin a cat (thoraco)}

\author{
Marvin D. Atkins, MD, and Michael J. Reardon, MD
}

Open thoracoabdominal aortic aneurysm repair has been one of the most demanding operations performed, both for the surgeon and the patient, since its original description by Etheridge and colleagues in $1955^{1}$ and popularized at our institution by Crawford and colleagues in the 1960 s. $^{2}$ Over the years, multiple variations in the steps of the operation and various adjuncts have been proposed to improve on the results and minimize the complications associated with these complex procedures. Perfusion adjuncts to avoid cardiopulmonary bypass and pump dose systemic heparinization have included the Gott shunt, ${ }^{3}$ in-line mesenteric shunting as described by Cambria and colleagues, ${ }^{4}$ and partial left heart bypass. The technique of "clamp and sew" for Crawford extent 1,2 , and 3 thoracoabdominal aortic aneurysm has for the most part been abandoned owing to the increased risk of spinal cord ischemia and visceral malperfusion.

In the current era of open thoracoabdominal aortic aneurysm repair, widely performed treatment perfusion strategies include full cardiopulmonary bypass, with or without deep hypothermia, and partial left heart bypass with sequential clamping. In this issue of JTCVS Techniques, Hiremath and colleagues ${ }^{5}$ describe the modified branch first technique of sequential mesenteric and left renal artery debranching with perfusion, followed by proximal and then distal aortic anastomoses. The technique involves cannulation of the descending thoracic aorta above the aneurysm or using left heart bypass with placement of the outflow cannula in the right renal limb of a branched thoracoabdominal graft. The celiac, superior mesenteric artery, and left renal artery are then sequentially debranched and perfused through the cannulated graft. This technique requires dissection of the mesenteric

From the Department of Cardiovascular Surgery, Houston Methodist Hospital, Houston, Tex.

Disclosures: The authors reported no conflicts of interest

The Journal policy requires editors and reviewers to disclose conflicts of interest and to decline handling or reviewing manuscripts for which they may have a conflict of interest. The editors and reviewers of this article have no conflicts of interest.

Received for publication March 13, 2021; revisions received March 13, 2021; accepted for publication March 22, 2021; available ahead of print March 26, 2021.

Address for reprints: Michael J. Reardon, MD, Department of Cardiovascular Surgery, Houston Methodist Hospital, 6550 Fannin St, Suite 1401, Houston, TX 77030 (E-mail: mreardon@houstonmethodist.org).

JTCVS Techniques 2021;7:34-5

2666-2507

Copyright (C) 2021 The Author(s). Published by Elsevier Inc. on behalf of The American Association for Thoracic Surgery. This is an open access article under the CC BY license (http://creativecommons.org/licenses/by/4.0/).

https://doi.org/10.1016/j.xjtc.2021.03.025

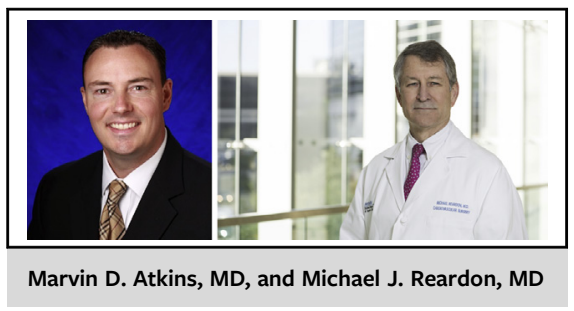

CENTRAL MESSAGE

Thoracoabdominal aortic aneu-

rysm repair is a complex pro-

cedure that has a number of

different technical approaches

to achieve success. Avoiding

ischemia in all areas is central to

all.

vessels and left renal artery well beyond their origins to place proximal and distal clamps and enough artery in between to sew to. In some patients, distal dissection of the celiac and superior mesenteric artery may prove quite difficult.

The authors propose that this technique limits spinal cord ischemia, as the aorta is perfused with pulsatile blood throughout the debranching portion of the procedure. The perfusion is then stopped before completion of the right renal artery bypass. The cannula is removed from the graft, and that limb is used for the right renal bypass. This portion of the procedure is similar to the technique described by Coselli, ${ }^{6}$ in which partial left heart bypass is transitioned to selective visceral perfusion via ostial cannulas and then stopped before the distal anastomosis. Our preferred technique is to continue perfusion to the distal aorta and iliac arteries throughout the operation, typically via left femoral artery cannulation. Griepp and Griepp ${ }^{7}$ have contributed extensively to our understanding of spinal cord perfusion, the "collateral network concept," and the importance of vertebral and iliac artery contributions to spinal cord perfusion.

Although the technique the authors describe is novel and avoids cardiopulmonary bypass, no definitive conclusions can be made about the purported benefits of spinal cord ischemia and visceral malperfusion. Clearly, when it comes to open thoracoabdominal aortic aneurysm repair, there is more than one way to skin a cat (thoraco).

\section{References}

1. Etheredge SN, Yee J, Smith JV, Schonberger S, Goldman MJ. Successful resection of a large aneurysm of the upper abdominal aorta and replacement with homograft. Surgery. 1955;38:1071-81. 
2. Garrett HE, Crawford ES, Beall AC Jr, Howell JF, De Bakey ME. Surgical treatment of aneurysm of the thoracoabdominal aorta. Surg Clin North Am. 1966;46: 913-8.

3. Valiathan MS, Weldon CS, Bender HW Jr, Topaz SR, Gott VL. Resection of aneurysms of the descending thoracic aorta using a GBH-coated shunt bypass. $J$ Surg Res. 1968;8:197-205.

4. Cambria RP, Davison JK, Giglia JS, Gertler JP. Mesenteric shunting decreases visceral ischemia during thoracoabdominal aneurysm repair. J Vasc Surg. 1998; 27:745-9.
5. Hiremath N, Younes H, Aleinati T, Park WM. Open repair of extent-II thoracoabdominal aortic aneurysm using a modified branch-first technique. J Thorac Cardiovasc Surg Tech. 2021;7:29-31.

6. Coselli JS. The use of left heart bypass in the repair of thoracoabdominal aortic aneurysms: current techniques and results. Semin Thorac Cardiovasc Surg 2003;15:326-32.

7. Griepp RB, Griepp EB. Spinal cord perfusion and protection during descending thoracic and thoracoabdominal aortic surgery: the collateral network concept. Ann Thorac Surg. 2007;83:S865-9; discussion S890-2. 